\title{
Physiotherapist as primary assessor for patients with suspected knee osteoarthritis in primary care-a randomised controlled pragmatic study
}

Chan-Mei Ho $\mathrm{O}^{1,2^{*}}$, Carina A. Thorstensson ${ }^{2,3}$ and Lena Nordeman ${ }^{2,4}$

\begin{abstract}
Background: In Swedish primary care, the healthcare process for patients with knee osteoarthritis (KOA) can be initiated by a physician or physiotherapist assessment. However, it is unclear how the different assessments affect the healthcare processes and patient reported outcomes over time. The purpose of this study was to examine the differences in health-related quality of life ( $\mathrm{HrQoL}$ ), adjusted for pain and physical function, for patients with KOA when the healthcare process is initiated by a physiotherapist assessment compared to a physician assessment in primary care.
\end{abstract}

Methods: An assessor-blinded randomised controlled pragmatic trial. Using a computer-generated list of random numbers, patients seeking primary care during 2013-2017 with suspected KOA were randomised to either a physiotherapist or physician for primary assessment and treatment. Data was collected before randomisation and at 3, 6, and 12-month follow-ups. Primary outcome was HrQoL using EuroQol 5 dimensions 3 levels questionnaire, index (EQ-5D-3L index) and a visual analogue scale (VAS) (EQ-5D-3L VAS); pain intensity was measured with VAS (0-100) and physical function measured with the 30-s chair stand test. Mixed effect model analyses compared repeated measures of HrQoL between groups. The significance level was $p<0.05$ and data was applied with intention-to-treat.

Results: Patients were randomised to either a physiotherapist $(n=35)$ or physician $(n=34)$ for primary assessment. All 69 patients were included in the analyses. There were no significant differences in HrQoL for patients assessed by a physiotherapist or a physician as primary assessor (EQ-5D-3L index, $p=0.18$; EQ-5D-3L VAS, $p=0.49$ ). We found that $\mathrm{HrQoL}$ changed significantly 12 months after baseline assessment for all patients regardless of assessor (EQ-5D-3L index, $p<0.001$; EQ-5D-3 L VAS, $p=0.0049$ ). No adverse events or side effects were reported.

Conclusions: There were no differences in HrQoL, when adjusted for pain and physical function, for patients with KOA when the healthcare process was initiated with physiotherapist assessment compared to physician assessment in primary care. Both assessments resulted in significantly higher HrQoL at the 12-month follow-up. The results imply that physiotherapists and physicians in primary care are equally qualified as primary assessors.

Trial registration: Retrospectively registered at http://clinicaltrial.gov, ID: NCT03715764.

Keywords: Delivery of health care, Disease management, Treatment outcome, Quality of life, Osteoarthritis, Knee

\footnotetext{
* Correspondence: chan-mei.ho@vgregion.se

${ }^{1}$ Region Västra Götaland, Närhälsan Health Unit, Primary Health Care,

Lidköping, Sweden

${ }^{2}$ Department of Health and Rehabilitation, Unit of Physiotherapy, University

of Gothenburg, Sahlgrenska Academy, Institute of Neuroscience and

Physiology, Gothenburg, Sweden

Full list of author information is available at the end of the article
}

C) The Author(s). 2019 Open Access This article is distributed under the terms of the Creative Commons Attribution 4.0 International License (http://creativecommons.org/licenses/by/4.0/), which permits unrestricted use, distribution, and reproduction in any medium, provided you give appropriate credit to the original author(s) and the source, provide a link to the Creative Commons license, and indicate if changes were made. The Creative Commons Public Domain Dedication waiver (http://creativecommons.org/publicdomain/zero/1.0/) applies to the data made available in this article, unless otherwise stated. 


\section{Background}

Osteoarthritis (OA) is one of the most common joint diseases and a major cause of chronic musculoskeletal pain and disability in working and older adults [1, 2]. In Sweden, 14\% of those over 45 are estimated having knee OA (KOA) [3]. Common OA symptoms are pain, morning stiffness, reduced range of motion, joint instability, swelling, muscle weakness and fatigue [4]. This directly affects patients' social interactions, mental functioning, and sleep quality [5], and patients with KOA report among the lowest health-related quality of life (HrQoL) compared with patients suffering other chronic diseases [6]. This patient group has a twofold risk for sick leave, and the diagnosis entails a $40-50 \%$ higher risk for disability pension. KOA accounts for $2 \%$ of all sick days in Sweden [2]. Patients with OA are less active and have more comorbidities than the overall population [7]. OA causes activity limitations, especially in walking [8]. Walking disability is related to a greater risk of mortality [9], which is largely explained by lack of physical activity [10-12].

Over the last 40 years, the proportion of overweight and obesity in the Swedish population have increased from $35 \%$ to $56 \%$ among men, and $27 \%$ to $41 \%$ among women [13]. This will probably affect the incidence of OA since overweight is a strong risk factor [14]. Consultations to healthcare are expected to increase by $30-50 \%$ among patients with OA over the next 10 years [15] and primary care physicians will probably face this predicted escalation in OA consultations [16].

Early access to a physiotherapist (PT) has previously been shown safe and effective for patients with musculoskeletal disorders [17, 18]. A pilot study showed that most patients assessed by a rehabilitation professional first (PT, occupational therapist, psychologist or counsellor) did not need to see a physician later [19]. PTs as primary assessors reduce referrals, sick leave, and prescriptions of analgesics for most musculoskeletal conditions [20]. Previous studies of back and neck pain have shown that the most common expectation when consulting a clinician (PT or physician) is not recovery, but having their diagnosis confirmed [21, 22], which is similar to what has been seen in patients with OA [23]. At the same time, patients with OA seem reluctant to seek professional help, partly because they wait until their problems affect their lifestyle or safety (e.g. risk of falling) [23, 24]. Later in the healthcare process, patients with OA feel unsure when to see their physician, they believe that physicians were more for initial diagnosis rather than following treatment [25-27].

Imaging is not required to diagnose a typical presentation of $\mathrm{OA}$ (i.e. usage-related pain, short duration morning stiffness, age $>40$, symptoms affecting one or more joints) [28]. Detectable radiographic changes are not always present in early OA $[29,30]$. When imaging is not required to diagnose typical symptomatic OA, both physicians and PTs can act as primary assessors. European League Against Rheumatism (EULAR) guidelines do not recommend any particular healthcare provider for the initial assessment since evidence of the effectiveness of various forms of assessment is lacking. The recommendation is that the initial assessment should use a biopsychosocial approach including physical status, activities of daily living, participation in work, leisure or education, mood and health education needs, health beliefs and motivation to self-manage [31]. Core treatment of OA should be individualized and include patient education, an exercise regimen, weight loss if overweight or obese, reduction of adverse mechanical factors, and consideration of walking aids [31, 32]. Muscle strengthening exercises and maintaining physical activities, give patients with $\mathrm{OA}$ a better chance to maintain their level of physical function [33]. Physical activity interventions should be delivered by healthcare providers competent in treating this patient group [34]. Advice on exercise and pain relief comprises the bulk of the PT assessment, in comparison with other medical staff members [35-37], providing a key role in the acute and long-term management of OA. Common PT management in Sweden includes a nationwide program called "Better management of patients with OA" (BOA), consisting of patient education and supervised exercise to increase patients' efficacy to self-manage the disease and increase their level of physical activity [38]. Participation in the Swedish BOA results in improvements in HrQoL, pain, and self-efficacy [39].

Management of expected increases in OA consultations by early referrals of patients with suspected OA to a PT could save time for primary care physicians and lead to fewer healthcare visits for patients. Early contact with a PT would also aid in assuring correct management through information about the disease and longterm guided strength training, physical performance and fitness. Today, in Swedish primary care, patients can access a PT without referral. Thus, patients with suspected KOA could have a first assessment by either a physician or a PT. However, it is unclear if there are differences between managements reflected in $\mathrm{HrQoL}$, pain and physical function. The purpose of this study was to examine the differences in HrQoL, adjusted for pain and physical function, for patients with KOA when the healthcare process is initiated with PT assessment compared to a physician assessment in primary care. We hypothesise that all patients with suspected KOA could be assessed initially by a PT in primary care, and then referred to a physician if required. 


\section{Methods}

\section{Study design}

This is a multicentre, assessor-blinded, randomised controlled pragmatic trial comparing primary assessment, diagnosis, and treatment either by a PT or physician in primary care. The study comprised a healthcare process initiated either by a PT or physician assessment. Measurements were taken before randomisation (baseline) and at the 3-, 6- and 12-month follow-ups. The participant flow is illustrated in Fig. 1. The Regional Ethical Review Board in Gothenburg approved the study (reference number: 979-12). The study was retrospectively registered at clinicaltrial.gov, ID: NCT03715764.

\section{Participants}

Participants were recruited from primary care centres and rehabilitation centres in primary care in southwestern Sweden from April 2013 to November 2017. There were only three recruiting primary care centres at the beginning of the trial, which appeared insufficient. One clinic withdrew due to organisational issues. It was decided to add more clinics to intensify patient inflow. Total recruiting units: 6 primary care centres and 3 rehabilitation centres in primary care. Inclusion criteria according to American College of Rheumatologys (ACR) clinical criteria, which were: age $\geq 38$ years, knee pain most days of the past month, morning stiffness $\leq 30 \mathrm{~min}$, and crepitus during active motion [40]. Exclusion criteria were knee pain due to trauma (i.e. not insidious debut), other diseases that could affect outcome measures (rheumatic or systemic diseases, severe somatic or mental diseases such as depression), pregnancy, or if already diagnosed or assessed by another healthcare provider due to current knee pain. The patient had to know enough Swedish to understand test instructions and complete selfadministered questionnaires. The screening procedure was modified after 20 patients to intensify patient inflow. Morning stiffness and crepitus on active motion were removed from the inclusion criteria. Nurses screened for eligible participants at the primary care centres, and receptionists at the rehabilitation centres in primary care. All participants received oral and written information about the study, and provided written informed consent.

\section{Sample size}

To detect a minimal clinical improvement in HrQoL of 0.121(SD 0.2) on the EuroQol 5 dimensions 3 level questionnaire (EQ-5D-3L) index [41, 42], with a two-sided $5 \%$ significance level and a power of $80 \%$, a sample size of 50 patients per group was found necessary, given an anticipated dropout rate of $14 \%$.

\section{Randomisation}

Using a computer-generated list of random numbers, participants were randomly assigned to initial assessment, diagnosis and treatment by either a PT or physician. Each primary care centre $(n=6)$ consisted of $6-11$ physicians and the rehabilitation centres in primary care $(n=3)$ had 3-10 PTs. One project coordinator was included from among healthcare providers in the study, but was neither involved in the screening procedures nor data collection. The project coordinator managed the sequence generation, allocation concealment, enrolment and assignments of participants, and kept the concealed randomisation scheme and sequentially numbered, sealed envelopes in a locked cupboard (in the same building as enrolment), available only to the project coordinator. The project coordinator revealed allocation to the participant and healthcare providers shortly after baseline measurement. Participants and healthcare providers in both groups were aware of the allocated group, whereas the data collector $(\mathrm{CH})$, data analyst $(\mathrm{CH})$ and statistician were blinded to allocation until completion of all outcome assessments. $\mathrm{CH}$ was not involved in assessing, diagnosing, or treating patients with KOA while the study was in progress.

\section{Interventions}

Patients were allocated to either a PT or physician for initial assessment, diagnosis and treatment. The assessments or treatments by either PT or physician were conducted in accordance with Swedish treatment guidelines [43] and could vary depending on the patients' symptoms. PT treatment could involve individual and/or group treatment. Individual treatment could include exercise regimen (PT led or home exercising), education, pain relief or walking aids. Group treatment included patient education and individualized exercise regimen, according to the BOA program [38]. BOA consisted of individual assessment, patient education (3 sessions), and six weeks of exercising (PT led or home exercising). Physician treatment could include prescriptions, referrals to $\mathrm{x}$-ray examination, a $\mathrm{PT}$, or another healthcare provider. With the purpose to examine daily clinical setting, patients could see the other healthcare provider at any time after the first assessment if needed. Consultations with other healthcare providers were registered between baseline and the 12-month follow-up. This data will be presented in a cost-efficiency study, registered at clinicaltrial.gov, ID: NCT03822533.

\section{Outcome measures}

The primary outcome measure was HrQoL, using EQ5D-3L $[41,44,45]$. The questionnaire contains five dimensions: mobility, self-care, usual activities, pain/discomfort and anxiety/depression. For each dimension, the patient can choose between three levels best describing how they experience their state of health on the day of measurement (no problems = level 1, some problems $=$ level 2 , or extreme problems $=$ level 3 ). The 


\section{Enrollment}

Assessed for eligibility ( $n=363$ )

Excluded $(n=294)$

- Not meeting inclusion criteria $(n=185)$

- Declined to participate $(n=15)$

- Excluded due to exclusion criteria $(n=94)$

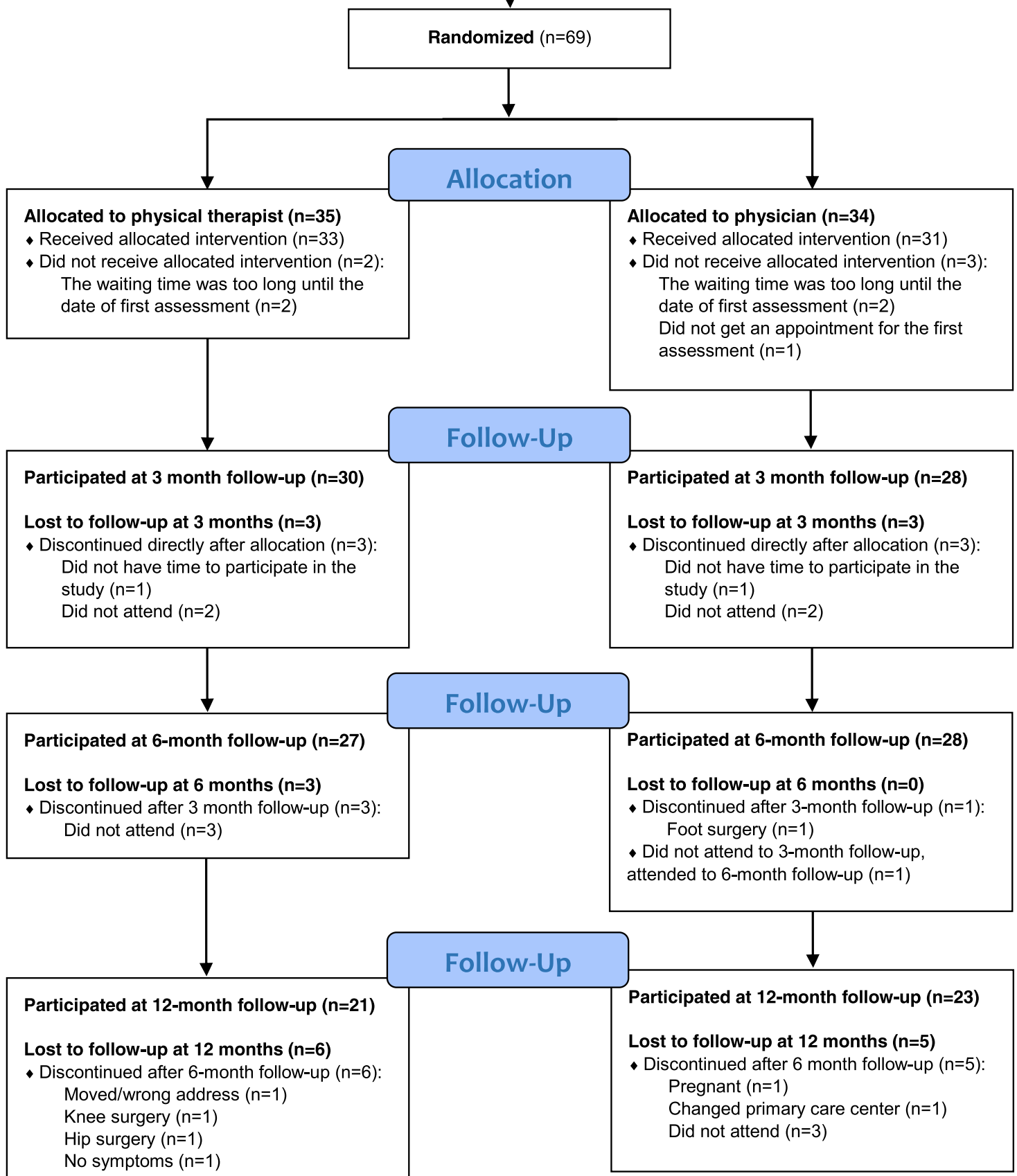

Fig. 1 The participant flow 
result of the questionnaire is an index on a scale between 1 and -0.594 calculated using the United Kingdom's value sets [46]. An index of 1 indicates full health. The EQ-5D-3L includes a visual analogue scale (EQ-5D-3L VAS), where the patient marks on a scale describing their health state on the day of measurement. The scale ranges from 0 to 100 , where 0 is the worst imaginable health state and 100 is the best imaginable health state [42, 44, 47]. EQ-5D-3L has shown good test-retest reliability and validity for patients with KOA [47].

Demographic data was collected at baseline, including age, sex, national origin, social status, level of education, employment, pain duration, and height and weight to calculate Body Mass Index (BMI). Pain intensity over the past month was measured by a visual analogue scale (VAS) [48] which ranged from 0 to 100; extreme points 0 and 100 were anchored with no pain and worst imaginable pain, respectively, 1-20 was anchored with light pain, 21-40 moderate pain, 41-60 moderately severe pain, 61-80 severe pain, and 81-99 unbearable pain. Physical function was measured using the 30-s Chair Stand Test (30CST) [49]. The score was the total number of stands executed correctly from sitting on a chair within $30 \mathrm{~s}$ (more than halfway up at the end of $30 \mathrm{~s}$ was considered a full stand). Incorrectly executed stands (incomplete stands, or not seated between the stands) were not counted.

\section{Statistical analysis}

Demographic data was analysed descriptively and presented as numbers and per cent, mean and standard deviation, and median and 25th to 75th percentiles. Mixed effect model analyses were used to compare the repeated measures of HrQoL between groups (EQ-5D$3 \mathrm{~L}$ index and EQ-5D-3L VAS). Independent variables in the model were checked for collinearity using Spearman's rank correlation coefficient $(r \leq 0.7)$, boxplot overlap, and cross tables (for $>80 \%$ observations in diagonal and cells $>5$ observations). The mixed effect model analysis consisted of two models, Model 1 and Model 2 . Model 1 (unadjusted): Variables: Group, Time and Group*Time (interaction between Group intervention and Time). Model 2 (final model with confounder adjustment): Based on Model 1, with confounder adjustment according to the criteria described below. Variables considered to be possible confounders were age, sex, body mass index (BMI), educational level, pain intensity and physical function. Possible confounders were added one at a time to Model 1, and carried forward to the final model if $p<0.20$. Variables (Group, Time ad Group*Time) in the final models were considered statistically significant if $p<0.05$. The model means will be presented in graphs to illustrate the direction of change in HrQoL and how the curves change during a 12month period of time. If differences were found between the groups' curves, additional analyses were made to examine possible significant differences in parts of the healthcare process. Data was analysed statistically in the Statistical Package for Social Science for Windows 22.0 [50]. Data was applied with intention-to-treat where patients received the randomised allocated intervention, i.e. the first assessment either by a PT or physician.

\section{Results}

To establish if HrQoL differed between the effects of being assessed by a PT or a physician for suspected KOA, 69 patients were randomised to either a PT or physician as primary assessor. Most of the patients, $79 \%$, participated in the 6-month follow up and 64\% completed the 12-month follow-up.

Demographic data and clinical characteristics are presented in Table 1. All 69 patients were included in the mixed effect model analyses. We found that HrQoL improved significantly 12 months after assessment for all patients regardless of assessor (variable "Time": EQ-5D$3 \mathrm{~L}$ index, $p<0.001$; EQ-5D-3L VAS, $p=0.0049)$. There were no significant differences in HrQoL between PTs and physicians as primary assessors (variable "Time"Group": EQ-5D-3 L index, $p=0.18$; EQ-5D-3 L VAS, $p=$ 0.49). See Table 2 for EQ-5D-3L index results and Table 3 for EQ-5D-3L VAS results. The final model of the EQ-5D$3 \mathrm{~L}$ index was adjusted for the confounder's sex, educational level, pain intensity and physical function. The final model of EQ-5D-3 L VAS was adjusted for the confounder's sex, pain intensity and physical function.

The model means for the EQ-5D-3L index increased for both groups. The physician group had a larger increase from baseline to the 12-month follow-up ( $\mathrm{PT}=+$ 0.084 , physician $=+0.181$ ). For the EQ-5D-3L VAS, the total increase from baseline to 12-month follow-up in model means was similar between groups $(\mathrm{PT}=+9$, physician $=+8$ ). The changes in model means are illustrated in Figs. 2 and 3 for adjusted models.

The model means showed an increase in EQ-5D-3L index for the physician group only for the period between baseline and the 3-month follow-up. Additional mixed effect model analyses were made for the first three months only. The final model showed no significant change in HrQoL for both groups (variable "Time": EQ-5D-3L index, $p=0.42$; EQ-5D-3L VAS, $p=0.99$ ), or significant differences between PTs and physicians as primary assessors (variable "Time*Group": EQ-5D-3L index $p=0.24$; EQ-5D-3L VAS, $p=0.55$ ). See Additional file $1 \mathrm{a}$ and $\mathrm{b}$.

\section{Discussion}

The findings of this study imply that PTs can be the first assessor when patients with suspected KOA seek 
Table 1 Demographic features of the groups at baseline assessment

\begin{tabular}{|c|c|c|}
\hline & Physical therapy assessment $(n=35)$ & Physician assessment $(n=34)$ \\
\hline & $\begin{array}{l}\text { Mean (SD); median } \\
\text { [25th to } 75 \text { th percentile] or } \% \text { (n) }\end{array}$ & $\begin{array}{l}\text { Mean (SD); median } \\
\text { [25th to } 75 \text { th percentile] or \% ( } n \text { ) }\end{array}$ \\
\hline Age (years) & $62(11.6) ; 63[52-71]$ & 59 (11.5); 57 [48-68] \\
\hline Sex (female) & $60 \%(21 / 35)$ & $68 \%(23 / 34)$ \\
\hline \multicolumn{3}{|l|}{ Origin } \\
\hline Born in Sweden & $86 \%(30 / 35)$ & $94 \%(32 / 34)$ \\
\hline \multicolumn{3}{|l|}{ Social status } \\
\hline Partner/Married & $89 \%(31 / 35)$ & $77 \%(26 / 34)$ \\
\hline \multicolumn{3}{|l|}{ Level of education } \\
\hline Primary school ( $\leq 9$ years) & $23 \%(8 / 35)$ & $12 \%(4 / 34)$ \\
\hline Secondary school (10-12 years) & $43 \%(15 / 35)$ & $59 \%(20 / 34)$ \\
\hline Tertiary school (> 12 years) & $34 \%(12 / 35)$ & $29 \%(10 / 34)$ \\
\hline \multicolumn{3}{|l|}{ Current employment } \\
\hline Employed/working & $54 \%(19 / 35)$ & $50 \%(17 / 34)$ \\
\hline Working rate (\%) & $88(4.7) ; 100$ [81-100] & $93(4.2) ; 100$ [100-100] \\
\hline Unemployed & $0 \%(0 / 35)$ & $3 \%(1 / 34)$ \\
\hline Retired/early retirement & $43 \%(15 / 35)$ & $38 \%(13 / 34)$ \\
\hline Sick leave & $3 \%(1 / 35)$ & $6 \%(2 / 34)$ \\
\hline Pain duration (months) & $14(22) ; 9$ [3-12] & $10(16) ; 4[2-11]$ \\
\hline $\mathrm{BMI} l^{\mathrm{a}}\left(\mathrm{kg} / \mathrm{m}^{2}\right)$ & $30(4.4) ; 29[26-31]$ & $29(6.7) ; 27[25-31]$ \\
\hline BMI: normal weight $(18,5-24,9)$ & $9 \%(3 / 35)$ & $29 \%(10 / 34)$ \\
\hline BMI: overweight $(25-29,9)$ & $54 \%(19 / 35)$ & $38 \%(13 / 34)$ \\
\hline BMl: obese (> 30) & $37 \%(13 / 35)$ & $32 \%(11 / 34)$ \\
\hline \multicolumn{3}{|l|}{$\mathrm{HrQoL}^{\mathrm{b}}(\mathrm{EQ}-5 \mathrm{D}-3 \mathrm{~L})$} \\
\hline Index & $0.73(0.121) ; 0.73[0.69-0.80]$ & $0.62(0.222) ; 0.73[0.62-0.73]$ \\
\hline VAS $(0-100)$ & 73 (17.5); 80 [68-90] & 68 (21.1), 70 [54-89] \\
\hline Pain intensity (VAS 0-100) & 45 (15.9); 47 [35-55] & $52(16.4) ; 51$ [40-69] \\
\hline Physical function $(30 \mathrm{CST})^{c}$ & $12(4.6) ; 12[9-14]$ & $11(3.3) ; 11$ [8-13] \\
\hline
\end{tabular}

${ }^{\mathrm{a}}$ Body Mass Index;

${ }^{\mathrm{b}}$ Health-related Quality of Life. Higher values indicate better health-related quality of life

c30-s Chair Stand Test. Higher values indicate better function

primary care for the first time. Our results are similar to previous findings showing that PTs are appropriate primary assessors for patients with musculoskeletal disorders [19, 20, 51]. PT as primary assessor is suggested as a model that uses healthcare resources more efficiently where the most appropriate healthcare professional assesses the patient's needs [52]. Several studies $[18,53-57]$ have reported that patients experienced as much or even greater patient satisfaction with a PT assessment than with physician assessment. Thus, using this model of care could require recruitment of more PTs, which could mean increased costs. Future research is needed to explore how patients with KOA experience PTs as primary assessors and the cost efficiency of this task-shifting model.
In this study, we found no statistically significant differences in HrQoL between groups 12 months after assessment. Even though the physician group had a 0.097 larger increase in model means for the EQ-5D-3L index 12 months after assessment, this does not exceed the minimal clinical difference of 0.121 . The reason for the large improvement in HrQoL for the physician group over the first three months could be related to the baseline mean value for the EQ-5D-3L index, which was much lower for the physician group when compared with the PT group. Patients allocated to a PT as primary assessor were somewhat older and had a slightly higher BMI at baseline. These patients also had longer pain duration, but graded lower pain intensity and had better physical function, which could also explain why patients 
Table 2 Mixed effect model analysis of EQ-5D-3L index - baseline to 12-month follow-up

\begin{tabular}{|c|c|c|c|c|c|c|c|c|}
\hline \multicolumn{9}{|c|}{ Mixed effect model analysis of EQ-5D-3L index - baseline to 12-month follow-up. } \\
\hline \multicolumn{2}{|c|}{ Model 1 (step 1) } & \multicolumn{6}{|c|}{ Model 1 with confounders (step 2) } & \multirow{2}{*}{$\begin{array}{c}\text { Model 2 (step 3, final) } \\
0.87\end{array}$} \\
\hline Group & 0.25 & 0.26 & 0.33 & 0.27 & 0.26 & 0.61 & 0.56 & \\
\hline Time & $<0.001^{*}$ & $<0.001^{*}$ & $<0.001^{*}$ & $<0.001^{*}$ & $<0.001^{*}$ & $<0.001^{*}$ & $<0.001^{*}$ & $<0.001^{*}$ \\
\hline Group x Time & 0.23 & 0.23 & 0.22 & 0.24 & 0.26 & 0.18 & 0.21 & 0.18 \\
\hline \multicolumn{2}{|c|}{ Potential confounder } & \multicolumn{6}{|c|}{ P-values for potential confounders when added one at a time } & \\
\hline & Age & 0.91 & & & & & & N/A \\
\hline & Sex & & 0.14 & & & & & 0.72 \\
\hline & $\mathrm{BMI}^{\mathrm{a}}$ & & & 0.54 & & & & N/A \\
\hline \multicolumn{2}{|c|}{ Educational level ${ }^{b}$} & & & & 0.018 & & & 0.053 \\
\hline \multicolumn{2}{|c|}{ Pain intensity ${ }^{c}$} & & & & & 0.0033 & & 0.012 \\
\hline \multicolumn{2}{|c|}{ Physical function ${ }^{d}$} & & & & & & $<0.001$ & 0.021 \\
\hline & & & & & & & & \\
\hline
\end{tabular}

Presenting $p$-values from regression analyses using mixed effect models

Model 1: Model included the variables Group, Time and Group x Time

Model 1 with confounder: Confounders were added separately to Model 1 . Confounding variables with $p$-values $<0.2$ were carried forward to the final model

Model 2: Final model, adjusted for confounders (sex, educational level, pain intensity and physical function)

Group: PT group resp. physician group

Time: Measurements at baseline, 3-, 6- and 12-month follow-ups

Group $x$ Time: Statistical interaction of group and time

aody Mass Index

${ }^{\mathrm{b}}$ Educational level, dichotomized variables - primary and secondary or tertiary school

'Pain intensity, VAS 0-100

dPhysical function, 30-s Chair Stand Test

*Statistically significant, $p<0.05$

Table 3 Mixed effect model analysis of EQ-5D-3L VAS - baseline to 12-month follow-up

\begin{tabular}{|c|c|c|c|c|c|c|c|c|}
\hline \multicolumn{9}{|c|}{ Mixed effect model analysis of EQ-5D-3L VAS - baseline to 12-month follow-up. } \\
\hline \multicolumn{2}{|c|}{ Model 1 (step 1) } & \multicolumn{6}{|c|}{ Model 1 with confounders (step 2) } & \multirow{2}{*}{$\begin{array}{c}\text { Model } 2 \text { (step 3, final) } \\
0.56\end{array}$} \\
\hline Group & 0.11 & 0.16 & 0.14 & 0.10 & 0.12 & 0.30 & 0.35 & \\
\hline Time & $0.0055^{*}$ & $0.0057^{*}$ & $0.0064^{*}$ & $0.0049^{*}$ & $0.0060^{*}$ & $0.0048^{*}$ & $0.0050^{*}$ & $0.0049^{\star}$ \\
\hline Group x Time & 0.41 & 0.40 & 0.45 & 0.43 & 0.40 & 0.48 & 0.44 & 0.49 \\
\hline \multicolumn{2}{|c|}{ Potential confounder } & \multicolumn{6}{|c|}{ P-values for potential confounders when added one at a time } & \\
\hline & $\mathrm{Age}$ & 0.25 & & & & & & $\mathrm{~N} / \mathrm{A}$ \\
\hline & Sex & & 0.14 & & & & & 0.69 \\
\hline & $\mathrm{BMI}^{\mathrm{a}}$ & & & 0.23 & & & & $\mathrm{~N} / \mathrm{A}$ \\
\hline \multicolumn{2}{|c|}{ Educational level ${ }^{\mathrm{b}}$} & & & & 0.22 & & & $\mathrm{~N} / \mathrm{A}$ \\
\hline \multicolumn{2}{|c|}{ Pain intensity ${ }^{c}$} & & & & & 0.021 & & 0.13 \\
\hline \multicolumn{2}{|c|}{ Physical function $^{d}$} & & & & & & $<0.001$ & $<0.001$ \\
\hline & & & & & & & & \\
\hline
\end{tabular}

Presenting $p$-values from regression analyses using mixed effect models

Model 1: Model included the variables Group, Time and Group x Time

Model 1 with confounder: Confounders were added separately to Model 1. Confounding variables with p-values $<0.2$ were carried forward to the final model

Model 2: Final model, adjusted for confounders (sex, pain intensity and physical function)

Group: PT group resp. physician group

Time: Measurements at baseline, 3-, 6- and 12-month follow-ups

Group x Time: Statistical interaction of group and time

${ }^{a}$ Body Mass Index

bducational level, dichotomized variables - primary and secondary or tertiary school

'Pain intensity, VAS 0-100

dPhysical function, 30-s Chair Stand Test

*Statistically significant, $p<0.05$ 
EQ-5D-3L index: Model 2 - Final model

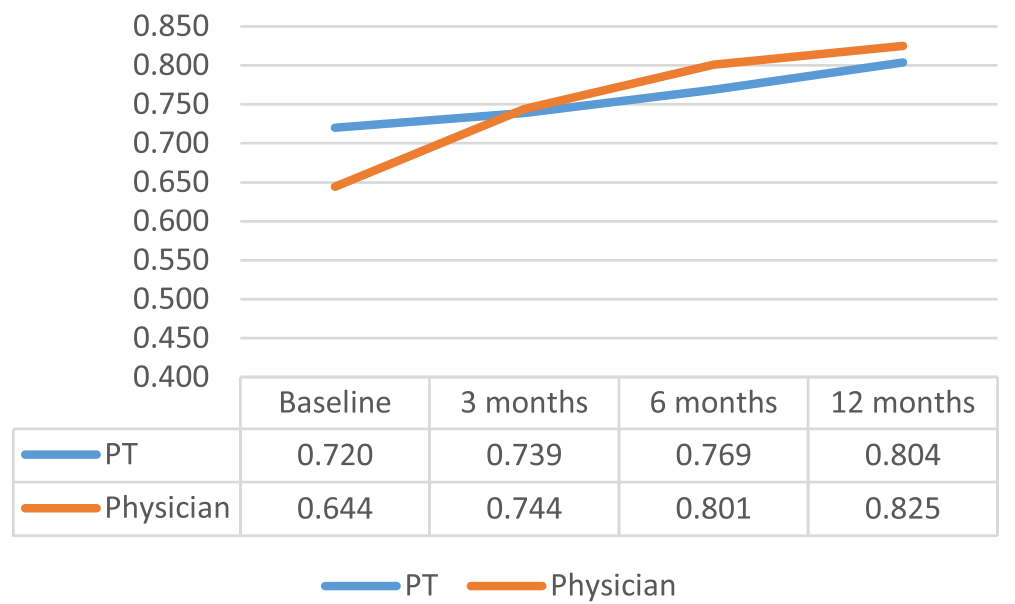

Fig. 2 Model means for EQ-5D-3L index, Model 2: adjusted model using confounders

in the PT group rated a higher HrQoL. The variation in the baseline values of EQ-5D-3L index were adjusted for in the mixed effect model analyses where patterns of change for each patient were used in the analysis [58]. The pragmatic study design might have contributed to a larger variation in patient characteristics within groups [59]. A larger sample size and/or use of a questionnaire with more levels such as EQ-5D-5L [60], could probably provide a better distribution of the EQ-5D index values at baseline.

Both groups improved in HrQoL 12 months after assessment. PT treatment in this study (i.e. the BOA program) were individualized, comprising patient education and exercise regime with the purpose of increasing patients' abilities to self-manage. This program has been developed in accordance with national and international guidelines [31, 32]. Participation in the BOA program decreases pain, and increases HrQoL and self-efficacy [39]. Exercise therapy, with or without being combined with other treatments, is an effective intervention to improve HrQoL in patients with $\mathrm{KOA}[61,62]$. It is possible that most patients in the present study received PT treatment, either by randomisation to a PT as primary assessor or were referred to a PT by a physician. This could explain why the improvements in $\mathrm{HrQoL}$ were seen in both groups. If there were no significant differences in HrQoL regardless of the primary assessor, and most patients probably ended up with PT treatment, one way to make the healthcare process more efficient for patients with KOA could

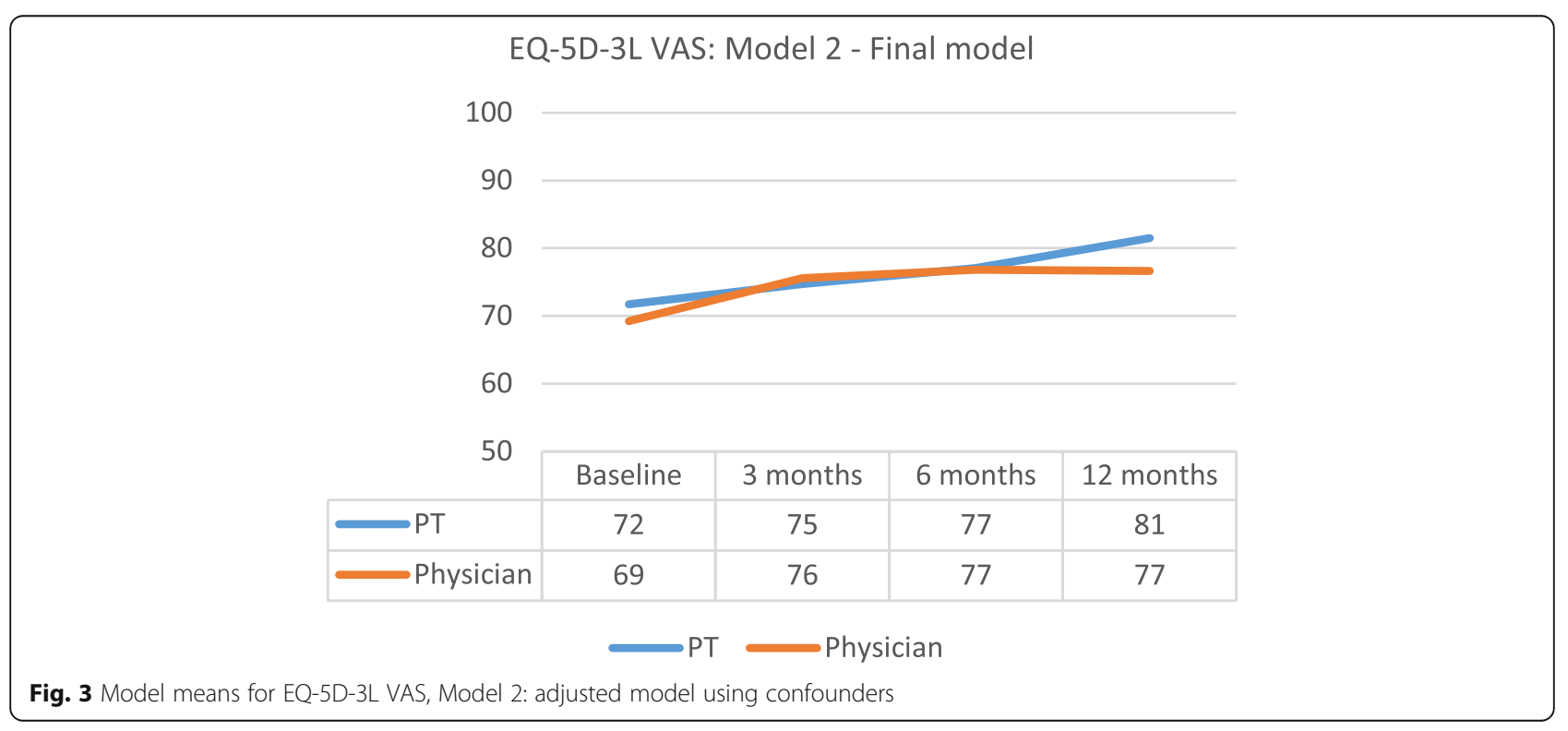


involve PTs as the sole primary assessor and use physicians when required.

Most patients were recruited from primary care centres, implying that they sought a physician consultation for their knee pain. It might be possible that the patients in the physician group were positively affected by the fact that they met a physician, which they expected from the beginning. Patients expect investigations such as $\mathrm{x}-$ rays or magnetic resonance imaging (MRI) to provide evidence of their experienced problem. Lack of these investigations could be experienced as a possible barrier for being understood and helped [63]. In this study, it could have led to higher satisfaction in the physician group due to receiving expected examinations and treatments, which could have affected the results with a higher $\mathrm{HrQoL}$, less pain and improved physical function because of decreased anxiety for their problems. It would have been interesting if the patients did not know what profession the primary assessor had in order to rule out a potential placebo effect. Unfortunately, this was not possible in this primary care setting because most primary care centres and rehabilitation centres in primary care have different locations.

Changing the inclusion criteria is one of the methodological limitations of this study. With two criteria removed, only age $>38$ years and knee pain without traumatic onset was used to detect suspected KOA. Wesseling et al. have been using knee pain and age over 45 as the only inclusion criteria when screening for early OA. None of the participants in their study had radiographic signs for OA, and 76\% fulfilled the clinical ACR criteria for KOA [64]. Another study [30] using only knee pain of less than three months' duration, age 3554 years, and no history of previous knee injury or inflammatory joint disease found that $70 \%$ had clinically classified OA according to ACR [40]. In the same study, they found that $86 \%$ of the patients with normal radiographs at baseline, later developed signs for fulfilling the criteria of radiographic OA (according to Kellgren/ Lawrence grade 1) in a 12-year period [30]. The motive for changing the inclusion criteria in this study was due to low patient inflow. The diagnostic accuracy of the ACR [40] clinical criteria for patients with early mild OA could have been too low. ACR clinical criteria seem to reflect later signs in advanced disease [65]. Future research would certainly benefit from specific criteria to detect early KOA to enhance the knowledge of early diagnosis and treatment in this stage of the disease.

One reason for the low patient flow could have been organisational, which involved both primary care centres and rehabilitation centres in primary care during the study period. The recruitment process was closed when no new participant was recruited for an entire year.
Ongoing reorganisation was probably given priority at the clinics instead of recruiting study participants. Despite reorganisation, similar Swedish clinical trials have had similar problems with low patient flow when recruiting participants to their studies [66, 67].

Due to the low patient flow, the required sample size of 100 patients was not reached, which is a limitation of this study. Sixty-nine participants were included at baseline, which increases the risk of a type II error in the study. The dropout rate was $40 \%$ for the PT group and $32 \%$ for the physician group at the 12-month follow-up. The benefits of an analysis with mixed effect models is that participants with missing data can be used in the analysis as long as the missing data is missing-atrandom. The missing value analysis for this study showed that the gender distribution, age range for the dropouts, and the reason for missing at follow-ups were similar in both groups (see Fig. 1). Mixed effect models handle the imbalanced data in available observations. Using mixed effect models is a strength of this study. The analysis is specifically designed for analysing data characterised by repeated measurements on the same individual [58]. The mixed effect models gave us a result showing how the primary assessment for patients with KOA affected their HrQoL 12 months after first assessment with consideration to possible confounders, which we cannot obtain from analyses with traditional statistical methods such as the Mann-Whitney U test.

A traditional randomised controlled trial with highly controlled treatments aim to test the true effect of a treatment, by ruling out placebo effects and extraneous effects (patient's or healthcare provider's knowledge or expectations of the treatment that could affect their behavior), and assuming that a patient group is homogenous. Compared to pragmatic trials, the generalizability for traditional randomised controlled trials are lower, since treatment outcomes would likely be affected by heterogeneous patient groups, placebo and extraneous effects which are present in the real clinic [59]. The pragmatic design is a strength of this study and the results have good external validity since the interventions have already been tested in a real clinical setting.

With this study, we showed that PTs and physicians did not differ as primary assessors for patients with suspected $\mathrm{KOA}$, regarding $\mathrm{HrQoL}$ up to 12 months after patients consulted primary care. These results support previous findings showing that PTs could be used as the primary assessor for patients with musculoskeletal disorders. Our results imply a task shift in primary care, which would probably enhance access for patients with $\mathrm{KOA}$ to a better OA management including core treatment of patient education and exercise. 


\section{Conclusions}

In this study, we found no differences in HrQoL, when adjusted for pain and physical function, for patients with KOA when the healthcare process was initiated with a PT assessment compared to a physician assessment in primary care. Both assessments resulted in significantly higher HrQoL at the 12-month follow-up. The results imply that PTs and physicians in primary care are equally qualified as primary assessors.

\section{Additional file}

Additional file 1: Tables of mixed effect models analysing EQ-5D-3L index and EQ-5D-3L VAS the first three months of the healthcare process. (DOCX $33 \mathrm{~kb}$ )

\begin{abstract}
Abbreviations
30CST: 30 seconds Chair Stand Test; ACR: American College of Rheumatology; BMI: Body mass index; CAT: Carina A Thorstensson (coauthor); $\mathrm{CH}$ : Chan-Mei Ho (corresponding author); EQ-5D-3L index: EuroQol 5 dimensions 3 levels questionnaire index; EQ-5D-3L VAS: EuroQol 5 dimensions 3 levels questionnaire visual analogue scale; EQ-5D-5L: EuroQol 5 dimensions 5 levels questionnaire; EULAR: European League Against Rheumatism; KOA: Knee osteoarthritis; LN: Lena Nordeman (co-author); n: Number; OA: Osteoarthritis; OARSI: Osteoarthritis research society international; PT: Physiotherapist/physiotherapy; SD: Standard deviation; VAS: Visual analogue scale
\end{abstract}

\section{Acknowledgements}

Not applicable.

\section{Authors' contributions}

All authors were responsible for concepts and design. $\mathrm{CH}$ was responsible for collection of data and its analysis. All authors together with a statistician interpreted the results. $\mathrm{CH}$ was a major contributor in writing the manuscript. LN and CAT were responsible for critical revisions of the article. All authors read and approved the final manuscript.

\section{Funding}

This study was financed by research grants from The Healthcare subcommittee, Region Västra Götaland, The Local Research and Development Council Fyrbodal, Swedish Rheumatism Association and Renée Enanders fund.

\section{Availability of data and materials}

The data sets generated and analysed during the current study are not publicly available due to the General Data Protection Regulation, which means that every participant's data is confidential, and unauthorized persons have no access to the dataset, but are available from the corresponding author on reasonable request.

\section{Ethics approval and consent to participate}

All participants received oral and written information about the study, and provided written informed consent. The Regional Ethical Review Board in Gothenburg approved the study, reference numbers: 979-12, T674-13, T497-14, T791-15.

\section{Consent for publication}

Not applicable.

\section{Competing interests}

The authors declare that they have no competing interests.

\section{Author details}

${ }^{1}$ Region Västra Götaland, Närhälsan Health Unit, Primary Health Care, Lidköping, Sweden. ${ }^{2}$ Department of Health and Rehabilitation, Unit of Physiotherapy, University of Gothenburg, Sahlgrenska Academy, Institute of Neuroscience and Physiology, Gothenburg, Sweden. ${ }^{3}$ Department of
Neurobiology, Care sciences and Society, Unit of Physiotherapy, Karolinska Institutet, Stockholm, Sweden. ${ }^{4}$ Region Västra Götaland, Närhälsan, Research and Development Primary Health Care, Research and Development Center Södra Älvsborg, Borås, Sweden.

Received: 14 March 2019 Accepted: 24 June 2019

Published online: 13 July 2019

\section{References}

1. Lawrence RC, Felson DT, Helmick CG, Arnold LM, Choi H, Deyo RA, Gabriel S, Hirsch R, Hochberg MC, Hunder GG, et al. Estimates of the prevalence of arthritis and other rheumatic conditions in the United States. Part II. Arthritis Rheum. 2008:58(1):26-35.

2. Hubertsson J, Petersson IF, Thorstensson CA, Englund M. Risk of sick leave and disability pension in working-age women and men with knee osteoarthritis. Ann Rheum Dis. 2013;72(3):401-5.

3. Turkiewicz A, Petersson IF, Bjork J, Hawker G, Dahlberg LE, Lohmander LS, Englund M. Current and future impact of osteoarthritis on health care: a population-based study with projections to year 2032. Osteoarthr Cartil. 2014:22(11):1826-32

4. Hunter DJ, McDougall JJ, Keefe FJ. The symptoms of osteoarthritis and the genesis of pain. Med Clin North Am. 2009;93(1):83-100 xi.

5. Ferrell BA. Pain management in elderly people. J Am Geriatr Soc. 1991;39(1): 64-73.

6. Picavet HS, Hoeymans $N$. Health related quality of life in multiple musculoskeletal diseases: SF-36 and EQ-5D in the DMC3 study. Ann Rheum Dis. 2004;63(6):723-9.

7. Gay C, Guiguet-Auclair C, Mourgues C, Gerbaud L, Coudeyre E. Physical activity level and association with behavioral factors in knee osteoarthritis. Ann Phys Rehabil Med. 2019;62(1):14-20.

8. Palazzo C, Ravaud JF, Papelard A, Ravaud P, Poiraudeau S. The burden of musculoskeletal conditions. PLoS One. 2014;9(3):e90633.

9. Nuesch E, Dieppe P, Reichenbach S, Williams S, Iff S, Juni P. All cause and disease specific mortality in patients with knee or hip osteoarthritis: population based cohort study. BMJ (Clinical research ed). 2011;342:d1165.

10. Barbour KE, Lui LY, Nevitt MC, Murphy LB, Helmick CG, Theis KA, Hochberg MC, Lane NE, Hootman JM, Cauley JA, et al. Hip osteoarthritis and the risk of all-cause and disease-specific mortality in older women: a population-based cohort study. Arthritis Rheumatol. 2015;67(7):1798-805.

11. Hawker GA, Croxford R, Bierman AS, Harvey PJ, Ravi B, Stanaitis I, Lipscombe LL. All-cause mortality and serious cardiovascular events in people with hip and knee osteoarthritis: a population based cohort study. PLoS One. 2014; 9(3):e91286

12. Hoeven TA, Leening MJ, Bindels PJ, Castano-Betancourt M, van Meurs JB, Franco OH, Kavousi M, Hofman A, Ikram MA, Witteman JC, et al. Disability and not osteoarthritis predicts cardiovascular disease: a prospective population-based cohort study. Ann Rheum Dis. 2015;74(4):752-6.

13. Varannan svensk har övervikt eller fetma. https://www.scb.se/hitta-statistik artiklar/2018/varannan-svensk-har-overvikt-eller-fetma/.

14. Oliveria SA, Felson DT, Cirillo PA, Reed JI, Walker AM. Body weight, body mass index, and incident symptomatic osteoarthritis of the hand, hip, and knee. Epidemiology (Cambridge, Mass). 1999;10(2):161-6.

15. Turkiewicz A, Petersson IF, Björk J, Dahlberg LE, Englund M. The consultation prevalence of osteoarthritis 2030 may increase by $50 \%$ : prognosis for Sweden. Osteoarthr Cartil. 2013;21(Supplement:S160-1).

16. Fehring TK, Odum SM, Troyer JL, lorio R, Kurtz SM, Lau EC. Joint replacement access in 2016. J Arthroplast. 2010;25(8):1175-81.

17. Holdsworth LK, Webster VS, McFadyen AK. What are the costs to NHS Scotland of self-referral to physiotherapy? Results of a national trial. Phys Ther. 2007:93:3-11.

18. Ludvigsson ML, Enthoven P. Evaluation of physiotherapists as primary assessors of patients with musculoskeletal disorders seeking primary health care. Physiotherapy. 2012;98(2):131-7.

19. Thorn J, Maun A, Bornhoft L, Kornbakk M, Wedham S, Zaffar M, Thanner C Increased access rate to a primary health-care Centre by introducing a structured patient sorting system developed to make the most efficient use of the personnel: a pilot study. Health Serv Manag Res. 2010;23(4):166-71.

20. Bornhoft $L$, Larsson ME, Thorn J. Physiotherapy in primary care triage - the effects on utilization of medical services at primary health care clinics by patients and sub-groups of patients with musculoskeletal disorders: a casecontrol study. Physiother Theory Pract. 2015;31(1):45-52. 
21. Verbeek J, Sengers MJ, Riemens L, Haafkens J. Patient expectations of treatment for back pain: a systematic review of qualitative and quantitative studies. Spine. 2004;29(20):2309-18.

22. Stenberg G, Fjellman-Wiklund A, Ahlgren C. "getting confirmation": gender in expectations and experiences of healthcare for neck or back patients. J Rehabil Med. 2012;44(2):163-71.

23. Smith TO, Purdy R, Lister S, Salter C, Fleetcroft R, Conaghan PG. Attitudes of people with osteoarthritis towards their conservative management: systematic review and meta-ethnography. Rheumatol Int. 2014;34(3): 299-313.

24. Thorstensson CA, Gooberman-Hill R, Adamson J, Williams S, Dieppe P. Helpseeking behaviour among people living with chronic hip or knee pain in the community. BMC Musculoskelet Disord. 2009;10:153.

25. Mann C, Gooberman-Hill R. Health care provision for osteoarthritis: concordance between what patients would like and what health professionals think they should have. Arthritis Care Res (Hoboken). 2011; 63(7):963-72.

26. Sanders C, Donovan JL, Dieppe PA. Unmet need for joint replacement: a qualitative investigation of barriers to treatment among individuals with severe pain and disability of the hip and knee. Rheumatology (Oxford). 2004:43(3):353-7.

27. Victor CR, Ross F, Axford J. Capturing lay perspectives in a randomized control trial of a health promotion intervention for people with osteoarthritis of the knee. J Eval Clin Pract. 2004;10(1):63-70.

28. Sakellariou G, Conaghan PG, Zhang W, Bijlsma JWJ, Boyesen P, D'Agostino MA, Doherty M, Fodor D, Kloppenburg M, Miese F, et al. EULAR recommendations for the use of imaging in the clinical management of peripheral joint osteoarthritis. Ann Rheum Dis. 2017;76(9):1484-94.

29. Thorstensson CA, Petersson IF, Jacobsson LT, Boegard TL, Roos EM. Reduced functional performance in the lower extremity predicted radiographic knee osteoarthritis five years later. Ann Rheum Dis. 2004;63(4):402-7.

30. Thorstensson CA, Andersson ML, Jonsson H, Saxne T, Petersson IF. Natural course of knee osteoarthritis in middle-aged subjects with knee pain: 12year follow-up using clinical and radiographic criteria. Ann Rheum Dis. 2009; 68(12):1890-3.

31. Fernandes L, Hagen KB, Bijlsma JW, Andreassen O, Christensen P, Conaghan PG, Doherty M, Geenen R, Hammond A, Kjeken I, et al. EULAR recommendations for the non-pharmacological core management of hip and knee osteoarthritis. Ann Rheum Dis. 2013;72(7):1125-35.

32. McAlindon TE, Bannuru RR, Sullivan MC, Arden NK, Berenbaum F, BiermaZeinstra SM, Hawker GA, Henrotin Y, Hunter DJ, Kawaguchi H, et al. OARSI guidelines for the non-surgical management of knee osteoarthritis. Osteoarthr Cartil. 2014;22(3):363-88.

33. Batsis JA, Germain CM, Vasquez E, Zbehlik AJ, Bartels SJ. Physical activity predicts higher physical function in older adults: the osteoarthritis initiative. J Phys Act Health. 2016;13(1):6-16.

34. Rausch Osthoff AK, Niedermann K, Braun J, Adams J, Brodin N, Dagfinrud H, Duruoz T, Esbensen BA, Gunther KP, Hurkmans E, et al. 2018 EULAR recommendations for physical activity in people with inflammatory arthritis and osteoarthritis. Ann Rheum Dis. 2018;77(9):1251-60.

35. Daker-White G, Carr AJ, Harvey I, Woolhead G, Bannister G, Nelson I, Kammerling M. A randomised controlled trial. Shifting boundaries of doctors and physiotherapists in orthopaedic outpatient departments. J Epidemiol Community Health. 1999;53(10):643-50.

36. Ball ST, Walton K, Hawes S. Do emergency department physiotherapy practitioner's, emergency nurse practitioners and doctors investigate, treat and refer patients with closed musculoskeletal injuries differently? Emerg Med J. 2007:24(3):185-8.

37. Richardson B, Shepstone L, Poland F, Mugford M, Finlayson B, Clemence N. Randomised controlled trial and cost consequences study comparing initial physiotherapy assessment and management with routine practice for selected patients in an accident and emergency department of an acute hospital. Emerg Med J. 2005;22(2):87-92.

38. Thorstensson CA, Garellick G, Rystedt H, Dahlberg LE. Better Management of Patients with osteoarthritis: development and Nationwide implementation of an evidence-based supported osteoarthritis self-management Programme. Musculoskeletal Care. 2015;13(2):67-75.

39. Jonsson T, Ekvall Hansson E, Thorstensson CA, Eek F, Bergman P, Dahlberg LE. The effect of education and supervised exercise on physical activity, pain, quality of life and self-efficacy - an intervention study with a reference group. BMC Musculoskelet Disord. 2018;19(1):198.
40. Altman R, Asch E, Bloch D, Bole G, Borenstein D, Brandt K, Christy W, Cookie TD, Greenwald R, Hochberg M, et al. Development of criteria for the classification and reporting of osteoarthritis. Arthritis Rheum. 1986;29(8): 1039-49.

41. Brazier JE, Harper R, Munro J, Walters SJ, Snaith ML. Generic and conditionspecific outcome measures for people with osteoarthritis of the knee. Rheumatology. 1999;38:870-7.

42. Walters SJ, Brazier JE. Comparison of the minimally important difference for two health state utility measures: EQ-5D and SF-36. Qual Life Res. 2005;14: 1523-32.

43. Nationella riktlinjer för rörelseorganens sjukdomar - 2012. Osteoporos, artros, inflammatorisk ryggsjukdom och ankyloserande spondylit, psoriasisartrit och reumatoid artrit. https://www.socialstyrelsen.se/ globalassets/sharepoint-dokument/artikelkatalog/nationella-riktlinjer/2012-51.pdf.

44. The EuroQol Group. EuroQol-a new facility for the measurement of healthrelated quality of life. Health Policy. 1990;16(3):199-208.

45. Brooks R. EuroQol: the current state of play. Health Policy. 1996;37(1):53-72.

46. Dolan P. Modeling valuations for EuroQol health states. Med Care. 1997; 35(11):1095-108.

47. Fransen M, Edmonds J. Reliability and validity of the EuroQol in patients with osteoarthiritis of the knee. Rheumatology. 1999;38:807-13.

48. Huskisson EC. Measurement of pain. Lancet. 1974;304(7889):1127-31.

49. Gill SD, de Morton NA, McBurney $\mathrm{H}$. An investigation of the validity in six measures of physical function in people awaiting joint replacement surgery of the hip or knee. Clin Rehabil. 2012;26(19):945-51.

50. Corp. I. IBM SPSS statistics for windows. In., 22.0 edn. Armonk, NY: IBM Corp. : Released; 2013.

51. Samsson KS, Larsson ME. Physiotherapy triage assessment of patients referred for orthopaedic consultation - long-term follow-up of healthrelated quality of life, pain-related disability and sick leave. Man Ther. 2015; 20(1):38-45.

52. Desmeules F, Roy JS, MacDermid JC, Champagne F, Hinse O, Woodhouse LJ. Advanced practice physiotherapy in patients with musculoskeletal disorders: a systematic review. BMC Musculoskelet Disord. 2012;13:107.

53. Razmjou H, Robarts S, Kennedy D, McKnight C, Macleod AM, Holtby R. Evaluation of an advanced-practice physical therapist in a specialty shoulder clinic: diagnostic agreement and effect on wait times. Physiother Can. 2013; 65(1):46-55

54. Robarts S, Kennedy D, MacLeod AM, Findlay H, Gollish J. A framework for the development and implementation of an advanced practice role for physiotherapists that improves access and quality of care for patients. Healthcare Q (Toronto, Ont). 2008;11(2):67-75.

55. Bath B, Janzen B. Patient and referring health care provider satisfaction with a physiotherapy spinal triage assessment service. J Multidiscip Healthc. 2012;5:1-15.

56. Desmeules F, Toliopoulos P, Roy JS, Woodhouse LJ, Lacelle M, Leroux M, Girard S, Feldman DE, Fernandes JC. Validation of an advanced practice physiotherapy model of care in an orthopaedic outpatient clinic. BMC Musculoskelet Disord. 2013;14:162.

57. Samsson KS, Bernhardsson S, Larsson ME. Perceived quality of physiotherapistled orthopaedic triage compared with standard practice in primary care: a randomised controlled trial. BMC Musculoskelet Disord. 2016;17:257.

58. Krueger C, Tian L. A comparison of the general linear mixed model and repeated measures ANOVA using a dataset with multiple missing data points. Biol Res Nurs. 2004;6(2):151-7.

59. Zuidgeest MGP, Goetz I, Groenwold RHH, Irving E, van Thiel G, Grobbee DE. Series: pragmatic trials and real world evidence: paper 1. Introduction. J Clin Epidemiol. 2017:88:7-13.

60. Agborsangaya CB, Lahtinen M, Cooke T, Johnson JA. Comparing the EQ-5D $3 \mathrm{~L}$ and $5 \mathrm{~L}$ : measurement properties and association with chronic conditions and multimorbidity in the general population. Health Qual Life Outcomes. 2014;12:74.

61. Briani RV, Ferreira AS, Pazzinatto MF, Pappas E, De Oliveira Silva D, Azevedo FM. What interventions can improve quality of life or psychosocial factors of individuals with knee osteoarthritis? A systematic review with meta-analysis of primary outcomes from randomised controlled trials. Br J Sports Med. 2018;52(16):1031-8.

62. Skou ST, Roos EM, Laursen MB, Rathleff MS, Arendt-Nielsen L, Simonsen O, Rasmussen S. A randomized, controlled trial of Total knee replacement. N Engl J Med. 2015;373(17):1597-606. 
63. Samsson KS, Bernhardsson S, Larsson ME. "Take me seriously and do something!" - a qualitative study exploring patients' perceptions and expectations of an upcoming orthopaedic consultation. BMC Musculoskelet Disord. 2017:18(1):367.

64. Wesseling J, Boers M, Viergever MA, Hilberdink WK, Lafeber FP, Dekker J, Bijlsma JW. Cohort profile: cohort hip and cohort knee (CHECK) study. Int J Epidemiol. 2016;45(1):36-44.

65. Whiting P, Rutjes AW, Reitsma JB, Glas AS, Bossuyt PM, Kleijnen J. Sources of variation and bias in studies of diagnostic accuracy: a systematic review. Ann Intern Med. 2004;140(3):189-202.

66. Bornhoft L, Larsson ME, Nordeman L, Eggertsen R, Thorn J: Health effects of direct triaging to physiotherapists in primary care for patients with musculoskeletal disorders: a pragmatic randomized controlled trial. Ther Adv Musculoskelet Dis 2019, 11:1759720X19827504.

67. Frobell RB, Lohmander LS, Roos EM. The challenge of recruiting patients with anterior cruciate ligament injury of the knee into a randomized clinical trial comparing surgical and non-surgical treatment. Contemp Clin Trials. 2007;28(3):295-302.

\section{Publisher's Note}

Springer Nature remains neutral with regard to jurisdictional claims in published maps and institutional affiliations.

- fast, convenient online submission

- thorough peer review by experienced researchers in your field

- rapid publication on acceptance

- support for research data, including large and complex data types

- gold Open Access which fosters wider collaboration and increased citations

- maximum visibility for your research: over $100 \mathrm{M}$ website views per year

At $\mathrm{BMC}$, research is always in progress. 